\title{
Visualisation of high-speed fracture phenomena
}

\author{
H. Sakamoto ${ }^{1}$, H. Kuramae ${ }^{2}$, S. Itoh $^{3}$ \& E. Nakamachi ${ }^{4}$ \\ ${ }^{1}$ Graduate School of Science and Technology, \\ Kumamoto University, Japan \\ ${ }^{2}$ Osaka Institute of Technology, Japan \\ ${ }^{3}$ Okinawa National College of Technology, Japan \\ ${ }^{4}$ Doshisha University, Japan
}

\begin{abstract}
An explosive can cause a huge fracture of energy at low doses. A small 'cullet' was generated by using this energy to crush a glass bottle, and the recycling efficiency improvement was examined. Up to now, the influence of the cullet sizes against the amount of explosive, the distance from the explosive to the glass bottles and the bottle arrangement have been studied. During this time, the fracture phenomenon of the glass bottle by an underwater shockwave has been analysed with a high-speed camera and FEM simulation.

Keywords: glass-recycle, cullet, underwater shockwave, high-speed fracture, FEM simulation.
\end{abstract}

\section{Introduction}

Glass bottles are widely used as a container for drinks, food and medicine through their ability to be sealed up, their transparency and their storage stability. Many of these glass bottles are reused as returnable bottles or recycled as the raw material of the glass container called 'cullet' that is crushed to small fragments $[1,2]$, or disposed as reclamation garbage. The small cullet can shorten the melting time of raw materials during the smelting process and an energy saving of about $2.5 \%$ can be achieved if the availability of the cullet increases by $10 \%$. So, the authors proposed a new effective cullet-generating technique. This technique is used via an underwater shockwave and explosive energy. Using this proposed technique, a large amount of glass bottles can be crushed 
instantaneously by a little energy. Up to now, the influence of the cullet sizes against the amount of explosive, the distance from the explosive to the glass bottles and the bottle arrangement have been studied [3].

In this study, the fracture phenomenon of the glass bottle by an underwater shockwave was analysed with a high-speed camera and FEM simulation in order to obtain the optimum explosive condition.

\section{Experiment}

\subsection{Experimental procedures}

The scheme of experimental apparatus is shown in fig. 1 . The experiment was conducted in an explosion-proof steel container, which had been filled with water. A glass bottle and explosive were set at this tank and crushed by an underwater shockwave. The explosive used was PETN (explosive rate: $6308 \mathrm{~m} / \mathrm{s}$ ), SEP and an electric detonator was used as an igniter. In order to visualise the underwater shockwave propagation and the bottle fracture behaviours caused by explosive energy, the shockwave propagation was analysed by high-speed camera (HTV-1) with two xenon flashlights and the fracture process was analysed by high-speed video camera (Pho54) with two xenon high-power mercury lamps. The glass fragments called 'cullet' were all collected after the explosive experiment, and the weights of each fragment size sifted by four kinds of sieve were measured.
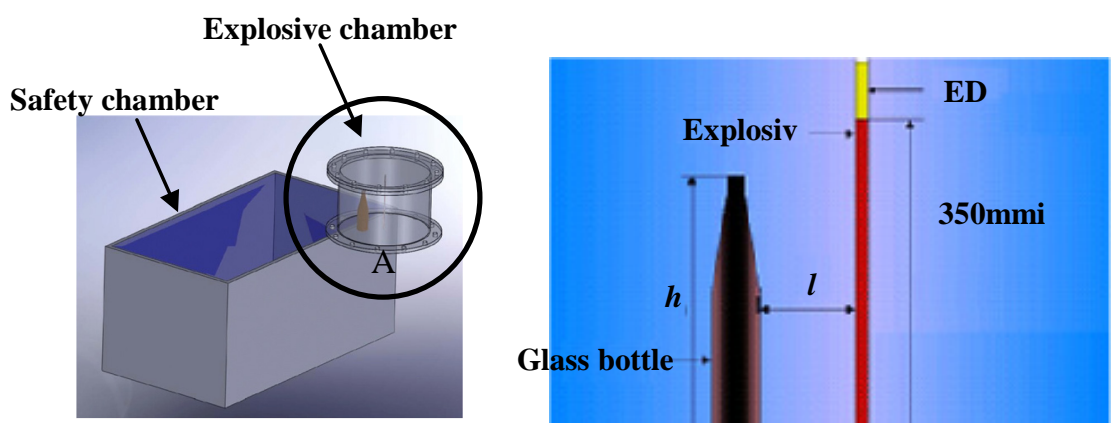

(a) Explosive units

(b) detail A: layout of bottle and explosive

Figure 1: $\quad$ Scheme of experimental apparatus.

\subsection{Specimen and experimental conditions}

The specimen is shown in fig. 2 . The specimen is used as a commercial beer bottle $(500 \mathrm{ml})$. The beer bottle was painted by five colours shown in fig. 3 to compare the cullet sizes by the bottle parts. Experimental conditions are shown in table 2 . The string-type (DF) explosives $(l=200 \mathrm{~mm}, 350 \mathrm{~mm})$ were used. The explosive used in this experiment contains PETN $1.0 \mathrm{~g} / 100 \mathrm{~mm}$. 


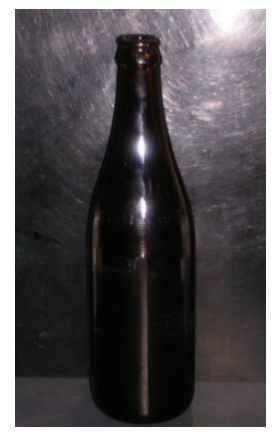

Figure 2: $\quad$ Specimen (beer bottle).

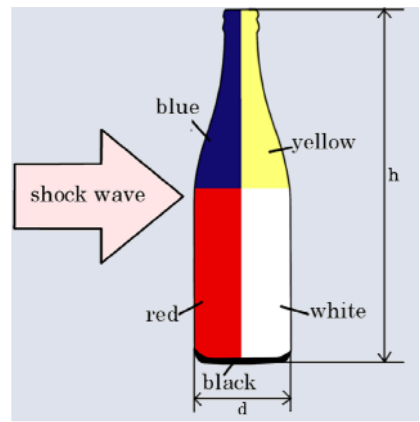

Figure 3: Colour-painted specimen.

The experimental conditions are shown in table 1.

Table 1: $\quad$ Experimental conditions.

\begin{tabular}{|c||c|c|c|c|c|c|c|c|}
\hline Table 2: & A & B & C & D & E & F & G & H \\
\hline \hline $\begin{array}{c}\text { Inside of } \\
\text { bottle }\end{array}$ & Air & Water & Water & Air & Air & Air & Air & Air \\
\hline Distance (mm) & 60 & 60 & 245 & 10 & 20 & 30 & 40 & 50 \\
\hline $\begin{array}{c}\text { Explosive } \\
\text { quantity (mm) }\end{array}$ & 200 & 200 & 200 & 350 & 350 & 350 & 350 & 350 \\
\hline
\end{tabular}

\subsection{Observation of the shockwave propagation and the fracture behaviour}

In order to visualise the behaviour of the underwater shockwave, the high speed photograph system was used, which consists of a high-speed camera (HTV-1) and xenon flashlight (H1/20/50 type). The optical observation system is shown in fig. 4. 


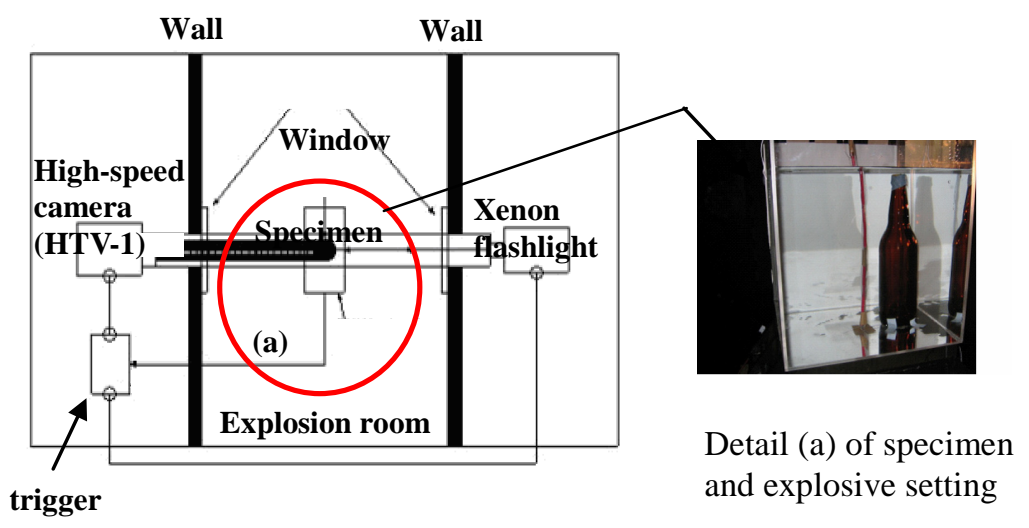

Figure 4: Optical observation system of shockwave propagation.

Table 3: $\quad$ The specification of high-speed video camera.

\begin{tabular}{|l|l|}
\hline Model-type & Ph05 \\
Product Co. & Nobby Tech. \\
Pixel & $256 \times 256$ \\
Pps & $1 / 36036$ \\
Exposure time & $25.75 \mu \mathrm{s}$ \\
\hline
\end{tabular}

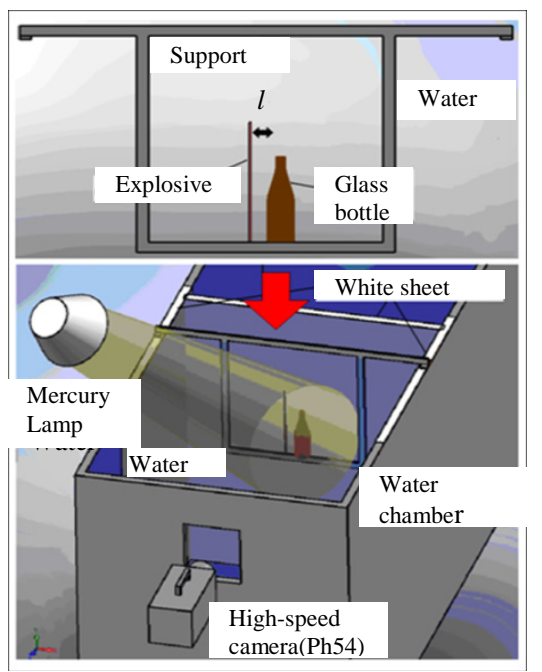

Figure 5: The bottle fracture behaviour observation system. 
The fracture behaviour was observed by a high-speed video camera (Ph54) and high-power mercury lamp. The layout of the measurement system and the specification of the high-speed video camera (Ph54) are shown in fig. 5 and table 2 , respectively.

\section{Experimental results}

\subsection{Cullet distributions}

The fragments of glass bottle were collected. These 'cullets' were classified by three kinds of sieve $(4.75 \mathrm{~mm}, 2 \mathrm{~mm}, 1 \mathrm{~mm})$ and each weight was measured.

The weight ratio in each experimental condition is shown in fig. 6 .

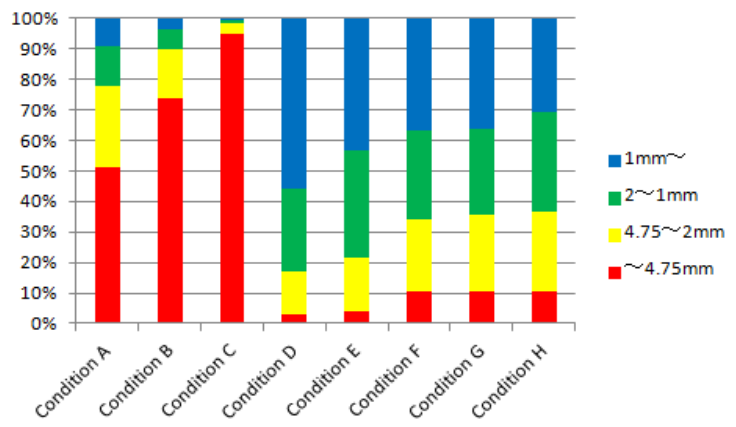

Figure 6: The distributions of cullet size (weight ratio).

In fig. 6, it can be seen that the small cullet ratio in the air case of bottle (Condition A) is large in comparison with that of water (Condition B). The weight of $1 \mathrm{~mm}$ or less cullet size decreases as the distance increases (Condition $\mathrm{C}-\mathrm{H}$ ) and in over $l=30 \mathrm{~mm}$, the small cullet ratio becomes almost the same (Condition $\mathrm{F}-\mathrm{H})$.

\subsection{The shockwave propagation behaviours}

The glass bottle was charged by the underwater shockwave and explosive as shown in fig.1. Here, the behaviours of underwater shockwave by explosive energy were observed by high-speed photography. The photograph was taken by a high-speed camera (HTV-1) and two xenon flashlights (H1/20/50type).

Fig. 7 shows the behaviours of shockwave propagation in the case of a stringtype explosive. The appearance of the shockwave propagation can be clearly observed from these figures. 


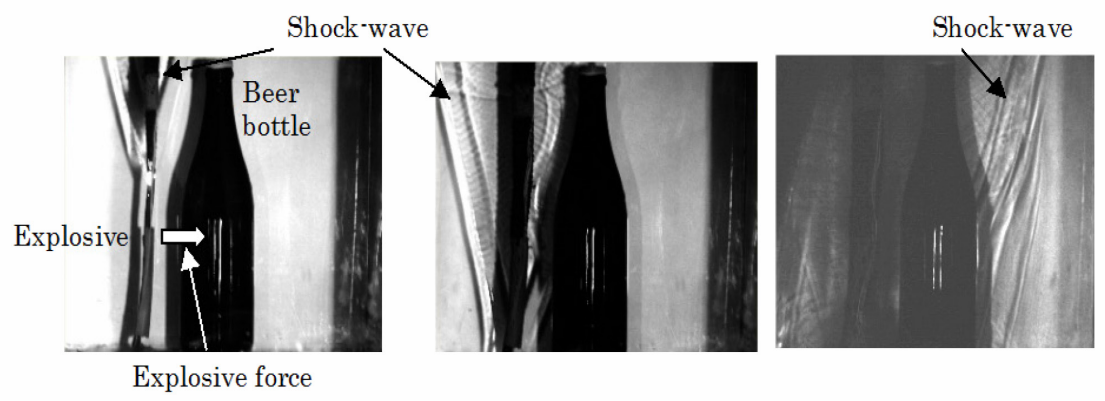

Figure 7: Underwater shockwave propagation.

\subsection{High-speed fracture behaviour of glass bottle by underwater shockwave}

Next, the high-speed behaviour of underwater shockwave by explosive energy was visualised by using a high-speed video camera with two mercury lamps. Framing photographs of the fracture process in the cases of condition A (inside air) and condition B (inside water) are shown in figs. 8 and 9.

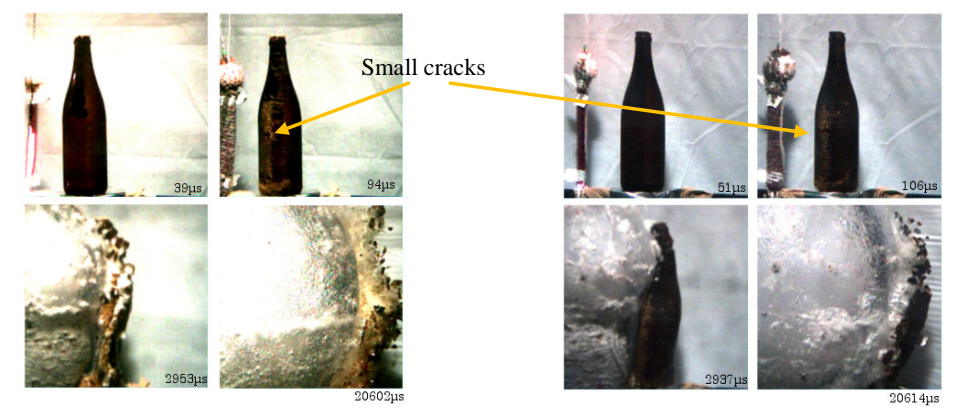

Figure 8: $\quad$ The glass bottle fracture $\quad$ Figure 9: $\quad$ The glass bottle fracture (inside air case) (inside water case). (Condition A).

An infinite number of small cracks occur on the surface of the bottle when the shockwave reaches the surface of the bottle. And the bottle breaks apart by the explosive gas generated afterwards. Comparing figs. 8 and 9, it is found that the fracture situation of the bottle in the case of inside air is more powerful than that of inside water. This cause originates in the compressibility of air.

\section{FEM simulation}

The fracture behaviours of the bottle submitted to underwater shockwave were simulated by using the commercial FEM code "LS-DYNA" [4]. Some examples of shockwave propagation behaviours obtained by analysis are shown in figs. 10 and 11. Fig. 10 shows the case of inside air and fig. 11 shows the case of inside water. 


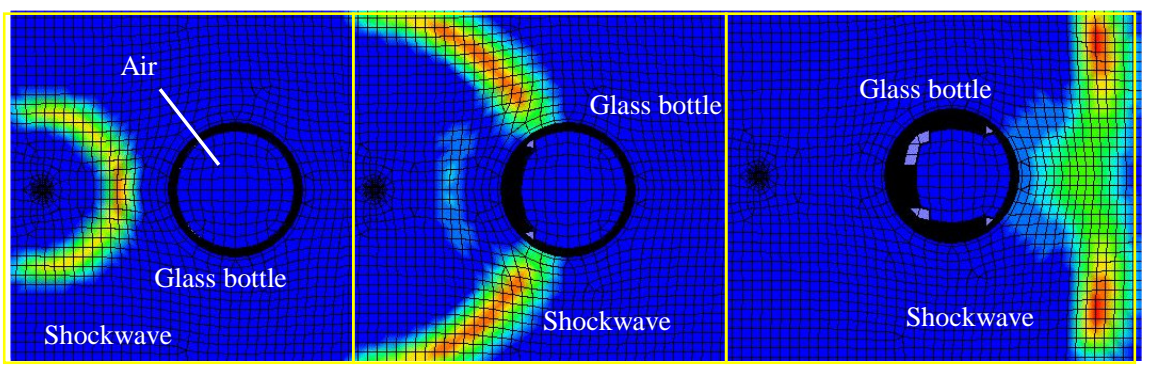

Figure 10: Shockwave propagation behaviour (inside air).

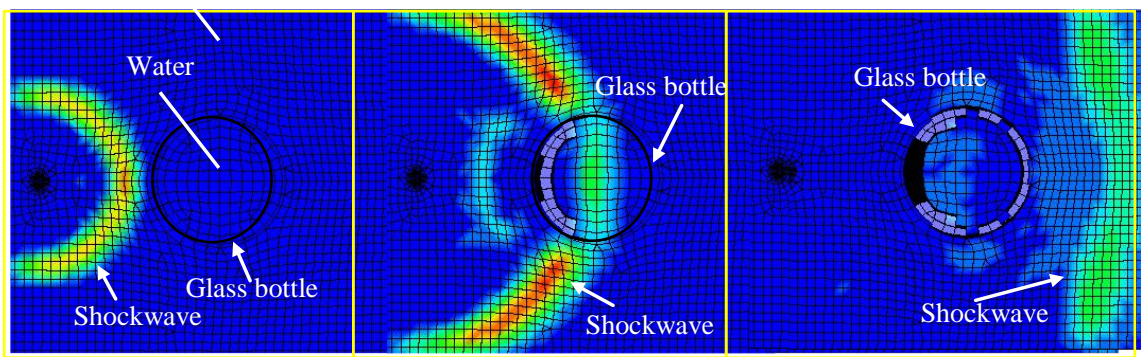

Figure 11: $\quad$ Shockwave propagation behaviour (inside water).

Three-dimensional simulation results correspond to the observations obtained by high-speed video system.

\section{Conclusions}

The shockwave propagation and high-speed fracture phenomenon of the glass bottle by explosive energy were analysed with a high-speed camera and FEM simulation for recycling of raw materials. The results obtained are summarised as follows:

(1) The cullet size distribution hardly depends on the distance between the explosive and specimen. The weight of $1 \mathrm{~mm}$ or less cullet size decreases as the distance increases and in over $l=30 \mathrm{~mm}$, small cullet ratio becomes almost the same.

(2) The appearance of the shockwave propagation can be clearly observed by using the high-speed camera with a flashlight.

(3) An infinite number of small cracks occurs on the surface of the bottle when the shockwave reaches the bottle's surface. And the bottle breaks apart by the explosive gas generated afterwards.

(4) The behaviour of the shockwave in the difference of contents of the bottle was confirmed by the analysis. 


\section{References}

[1] Sakka, S, The dictionary of glass, Asakura Press Ltd., 1998.

[2] Kobayashi, A.S., Experimental techniques in fracture mechanics, Society for Experimental Stress Analysis, 1973.

[3] Sakamoto, H., et al, Materials Science Forum, 566, pp. 231-236, 2008.

[4] Shim, V.P.W., Tanimura, S., Lim, C.T. Impact Response of Materials \& Structure, Oxford University Press, 1999. 